\title{
A fuzzy decision-support system in road safety planning
}

Hamid Reza Behnood PhD

Assistant Professor, Civil Engineering Department, Imam Khomeini International University, Qazvin, Iran (corresponding author: behnood@eng.ikiu.ac.ir)

Esmaeel Ayati PhD

Professor, Techno-Economic Road Safety Research Center, Department of Civil Engineering, Faculty of Engineering, Ferdowsi University of

Mashhad, Mashhad, Iran

\section{Tom Brijs PhD}

Professor, Transportation Research Institute (IMOB), Hasselt University, Diepenbeek, Belgium
Mohammadali Pirayesh Neghab PhD

Assistant Professor, Department of Industrial Engineering, Faculty of Engineering, Ferdowsi University of Mashhad, Mashhad, Iran

\section{Yongjun Shen PhD}

Professor, Transportation Research Institute (IMOB), Hasselt University, Diepenbeek, Belgium

The objective of this research was to develop a decision-support system to help road safety policy makers make the right choices in road safety planning based on the efficiency of previously implemented safety measures. The measures considered for each region in the study include performance indicators about police operations, treated black spots, freeway and highway facility supplies, speed control cameras, emergency medical services and road lighting projects. To this end, an inefficiency measure is calculated, defined by the proportion of fatality rates in relation to the combined measure of road safety performance indicators, which should be minimised. The relative inefficiency for each region is modelled using the data envelopment analysis (DEA) technique, which follows a benchmarking and target-setting process. In the next step, a fuzzy decision-making system is constructed to convert the information obtained from the DEA into a rule-based system that can be used by policy makers to evaluate the expected outcomes of certain alternative investment strategies in road safety. Using the resultant fuzzy decisionsupport system, policy makers can analyse alternative strategies in addition to those unique targets suggested by the DEA benchmarking and target-setting process.

\section{Notation}

$A_{i} \quad$ the fuzzy sets that state the verbal characteristics of the six variables

$B$ number of benchmarks for inefficient unit $A$ BS performance indicator for treated black spots

$\mathrm{DoS}_{h} \quad$ degree of satisfaction for hypothesis $h$ in all experienced samples

EMS performance indicator for emergency medical services

FR1 fatality risk per unit value of mobility demand

FR2 fatality risk per unit value of road length

$H_{i} \quad i$ th hypothesis in the fuzzy rule base

HEF performance indicator for freeways and highways

II inefficiency index that must be minimised

$\mathrm{II}_{A} \quad$ inefficiency index for inefficient unit $A$

$\mathrm{Li} \quad$ performance indicator for road lighting projects

PO performance indicator for police operation

$R \quad$ master set for the fuzzy rule block

SCC performance indicator for speed control cameras

$u_{1}, \ldots, u_{6} \quad$ reference sets for the premises in the fuzzy reasoning model

$u_{1}, u_{2} \quad$ output coefficients in DEA model

$V \quad$ reference sets for the conclusions in the fuzzy reasoning model

$v_{1}, v_{2} \quad$ input coefficients in DEA model

$\mathrm{WFI}_{r} \quad$ weighted fatality index for risk index type $r$

$\mathrm{WPI}_{i} \quad$ weighted performance indicator for $i$ th input $w \quad$ the adjusted value for each rule

$x_{i, b} \quad$ existing value of input data $i$ in benchmark $b$

$x_{1}, x_{2} \quad$ values for the inputs in DEA model

$y_{1}, y_{2} \quad$ values for the outputs in DEA model

$\alpha_{i} \quad$ the crisp value for the input indicator $i$

$\theta \quad$ objective value for DEA model

$\lambda_{b} \quad$ dual price for benchmark $b$

$\lambda_{j} \quad$ the dual price for the $j$ th decision making unit

$\mu_{A}\left(u_{i}\right) \quad$ fuzzy membership values for premises

$\mu_{B}(\beta) \quad$ the area under the membership function of the conclusion

$\mu_{B}(v) \quad$ fuzzy membership values for the conclusion

$\mu(\beta) \quad$ the adjusted value of the conclusion function for the related rule

$\mu_{B}^{(j)}(\beta) \quad$ the concluded fuzzy value of rule $j$

$\mu_{h}\left(x_{i}\right) \quad$ degree of satisfaction for hypothesis $h$ in sample element $i$

$\omega$ the concluded fuzzy value of rule $j$

\section{Introduction}

Future investments in road safety should benefit from an effectiveness evaluation regarding the safety outcomes realised. Recent studies have tried to use composite indicators to discuss the efficiency concept of road safety measures by quantitative analysis methods such as data envelopment analysis (DEA). These studies could have obtained brilliant results, especially using benchmarking and target-setting approaches. However, 
the results are restricted to a single strategy for each decision making unit (DMU). Thus, if a road safety agency cannot fully afford the inflexible targets dictated by the DEA model, no further alternatives can be examined for the same unit. Enabling road safety policy makers to examine flexible alternatives is the main contribution of the current study and one that adds value to the initial strategies resulting from DEA.

The objective of this study was therefore to develop a decisionsupport system (DSS) that brings together information from previously implemented road safety measures applied by different road safety agencies in order to predict the outcome of multiple decisions that can be made by road safety policy makers. Using a DSS, policy makers can analyse alternative strategies to those unique targets suggested by the DEA benchmarking and target-setting process. Here, a fuzzy decisionsupport system (FDSS) is introduced that can best simulate the decision-making process and predict decision outcomes on the basis of fuzzy rules that are pulled out from a set of previously experienced outcomes. The system serves the purpose of supporting future road safety decisions based on information on the efficiency of different types of measures taken previously. More specifically, this efficiency, expressed as an index, is calculated based on historical information from previously implemented measures across different regions in Iran. In a report prepared by the Road Safety Commission in Iran (RSCI), a full set of indicators in all road safety-related sectors was suggested as a guideline in collecting important safety-related data (RSCI, 2007). The identified indicators are all linked to road safety measures that contribute to achieving sustainable road safety. Based on the indicators suggested in the RSCI report, but taking into account a number of relevant quality criteria (see Section 2), a subset of indicators was selected for this study. Conventional statistical approaches are usually applied to model the frequency of road accidents or fatalities. Since this work deals with inefficiency outcomes, not with crash or fatality outcomes, a conventional statistical approach may not help in establishing a decision-making model to predict the inefficiency outcomes. Therefore, in this case, a reasoning approach can best help in simulating the real world. It should be noted that, depending on the existing situation of a given region, the model will either encourage decision makers to invest more in road safety measures or show the boundaries where efficient investments in road safety measures can be taken. Two main techniques will be applied. Having calculated the fatality rates in each region, the inefficiency is measured by DEA. After this, the planning task can be fulfilled through a fuzzy decision-making system involving a reasoning procedure.

Reviews on three decades of practice in DEA applications have created a mature perspective on methodology developments in a variety of industrial and managerial activities (Cook and Seiford, 2009; Emrouznejad et al., 2008). Due to its strong analytical capabilities, DEA has recently received increasing attention in the road safety literature as a tool for performance evaluation. For example, Hermans et al. (2009) presented a DEA model in which safety outcomes (crash and fatality risk) were combined with a set of safety performance indicators related to alcohol and drugs, speed, protective systems, trauma management, infrastructure and vehicles in 21 European countries. Their study introduced an upfront and advantageous methodology in prioritising road safety measures in a set of regions by benchmarking approaches, and the exact efficient targets can be estimated as well. The only limitation of this study is the lack of flexibility for checking the outcomes of other alternatives for a given DMU where the strategy recommended by the DEA process is not affordable - this is the issue addressed in the current research. Shen et al. (2011) used a multiple-layer DEA approach to model the hierarchical structure of safety indicators to give a more detailed insight into the layered architecture of road safety indicators. The methodology permitted the DEA to use a wider range of indicators for a given set of regions so that a more balanced model could be obtained and fewer units were identified as efficient. In subsequent work, Shen et al. (2012) used the DEA approach as a means to evaluate road safety risk and benchmark European countries in order to set practical targets for road safety improvements.

The other technique applied in this study as a decision-making tool is the fuzzy reasoning approach. Fuzzy reasoning methods enable the creation of prediction models that could not easily be made by conventional statistical models such as regression models. Recent works have shown some promising results in utilising fuzzy decision-making approaches in road safety planning. Cafiso et al. (2004) presented a fuzzy model to classify roadway elements with respect to their actual variation in accident rates with the aim of obtaining a more careful evaluation of highway design inconsistencies. Shi (2009) developed an evaluation index system for city traffic safety development that included safety policy for road traffic, the circumstance of road traffic safety, management of road traffic safety and control levels for road traffic accidents. Ma et al. (2009) selected preliminary indicators for road safety evaluation by integrating fuzzy characteristics of road traffic safety in China. Shen et al. (2010) presented a hybrid system of neural networks and rough sets for road safety performance indicators (RSPIs). The evaluation results imply the feasibility of this intelligent DSS and valuable predictive power for the road safety indicators context. In a similar work, Bao et al. (2012) proposed an improved hierarchical fuzzy Topsis (technique for order of preference by similarity to ideal solution) model to combine a set of multi-layered RSPIs into a composite index by incorporating expert knowledge.

\section{Road safety performance indicators}

In general, an RSPI is defined as any measure that is causally related to accidents or injuries, and is typically used in addition to a count of accidents or injuries in order to indicate safety performance or understand the process that leads to accidents (ETSC, 2001). Safety performance indicators refer to operators' 
activities within a transport system, but need not to be limited to this. Safety performance indicators are important components in a targeted safety programme, but are useful even if no such targeted programme has been adopted (ETSC, 2001). The three main functions of indicators as defined by Adriaanse (1993) are simplification, quantification and communication. Indicators thus try to capture complex phenomena in relatively simple terms. Indicators generally use simplification to make complex phenomena quantifiable in such a manner that communication is either enabled or promoted. Furthermore, indicators can be used to compare, rank and benchmark countries (or provinces in the current study) (Wegman and Oppe, 2010).

The RSPIs defined as the inputs of the current study can be categorised as implementation and policy performance indicators. However, some criteria apply to the selection of an appropriate set of indicators based on the list introduced by the RSCI (2007).

- For each of the indicators, at least 1 year of valid data for all provinces should be available. Furthermore, data from official reports that are annually issued by governmental agencies are an important requirement.

- Indicators should be relevant and actionable towards the typical activities of highway infrastructure agencies.

- There is a limit to the amount of input indicators to be used in the DEA. Mehregan (2006) proposed the following formula to determine the number of input and output indicators for a given set of DMUs

$$
\begin{array}{r}
\text { Number of DMUs } \geq \\
3 \times(\text { number of inputs } \\
+ \text { number of outputs })
\end{array}
$$

Otherwise, too many DMUs will be located on the efficiency boundary.

- The input datasets must be independent of each other. In other words, none of the indicators used should be a function of another one so that no collinearity exists in the dataset.

Based on the set of indicators proposed by the RSCI (2007) and taking into account the above-defined selection criteria, the following six indicators were selected as inputs for this study.

- Police operation (PO), defined as the average number of highway police stations per $100 \mathrm{~km}$ of road per region.

- Treated black spots (BS), defined as the average number of black spots treated per $100 \mathrm{~km}$ of road per region.

- Freeways and highways (H\&F), defined as the proportion of highway and freeway roads expressed as the sum of kilometres of both type of roads relative to the total length of roads in that region.

- Speed control cameras (SCC), defined as the average number of fixed speed cameras per $100 \mathrm{~km}$ of road per region.
- Emergency medical services (EMS), defined as the average number of roadside stations providing emergency medical services per $100 \mathrm{~km}$ of road per region.

- Road lighting projects (Li), defined as the average length of roads equipped with lighting poles per $100 \mathrm{~km}$ of road per region.

In addition to this set of input indicators, risk indices reflecting the fatality rates comprise the output values in this study. The risk indices as the output of the DEA are fatality rates involving the following two aspects of road fatality risk.

- FR1, the risk per unit value of mobility demand (number of fatalities per million vehicle-kilometres (vkm) travelled per region).

- FR2, the risk per unit value of road (number of fatalities per $100 \mathrm{~km}$ of road per region).

These two types of risk refer to all types of roads in a region as well as the mobility demand, which includes the total vkm travelled.

\section{Concepts and methods}

\subsection{Conceptual model}

The objective of this study was to create a DSS that enables the user to monitor historic performance, analyse the existing status and forecast the outcome of future policy decisions to maximise the efficiency of future road safety measures. The term 'efficiency' in this study reflects the revenue for implementing a set of road safety measures. The revenue rate is defined as the 'safety' value divided by the magnitude of road safety measures. As already noted, the main objective is to make a tool to maximise efficiency. However, the 'safety' value cannot be directly quantified, hence the inverse value (counted by fatality risk measures) is used and the resulting proportion is called the 'inefficiency' measure, which must be minimised. To this end, a two-stage process is undertaken.

In the first step, a DEA for each region is carried out on the basis of 2 years of input and output indicator data. The result of this step includes estimating a relative inefficiency index that must be minimised for each DMU per 2 years. Then, the units that perform well are identified as benchmarks by which the optimised target values are estimated for underperforming units.

In the second step, from the individual efficiency information per region obtained in the first step, a set of fuzzy decision rules that hold for the entire set of regions is derived. In other words, a set of generalised decision rules is derived to represent 'best practices' that can be adopted by all regions. In this way, in the process of road safety planning, each individual region can take advantage of the collective knowledge base of efficiency information for all policy measures from all regions to formulate rapidly and more consciously which combination of 


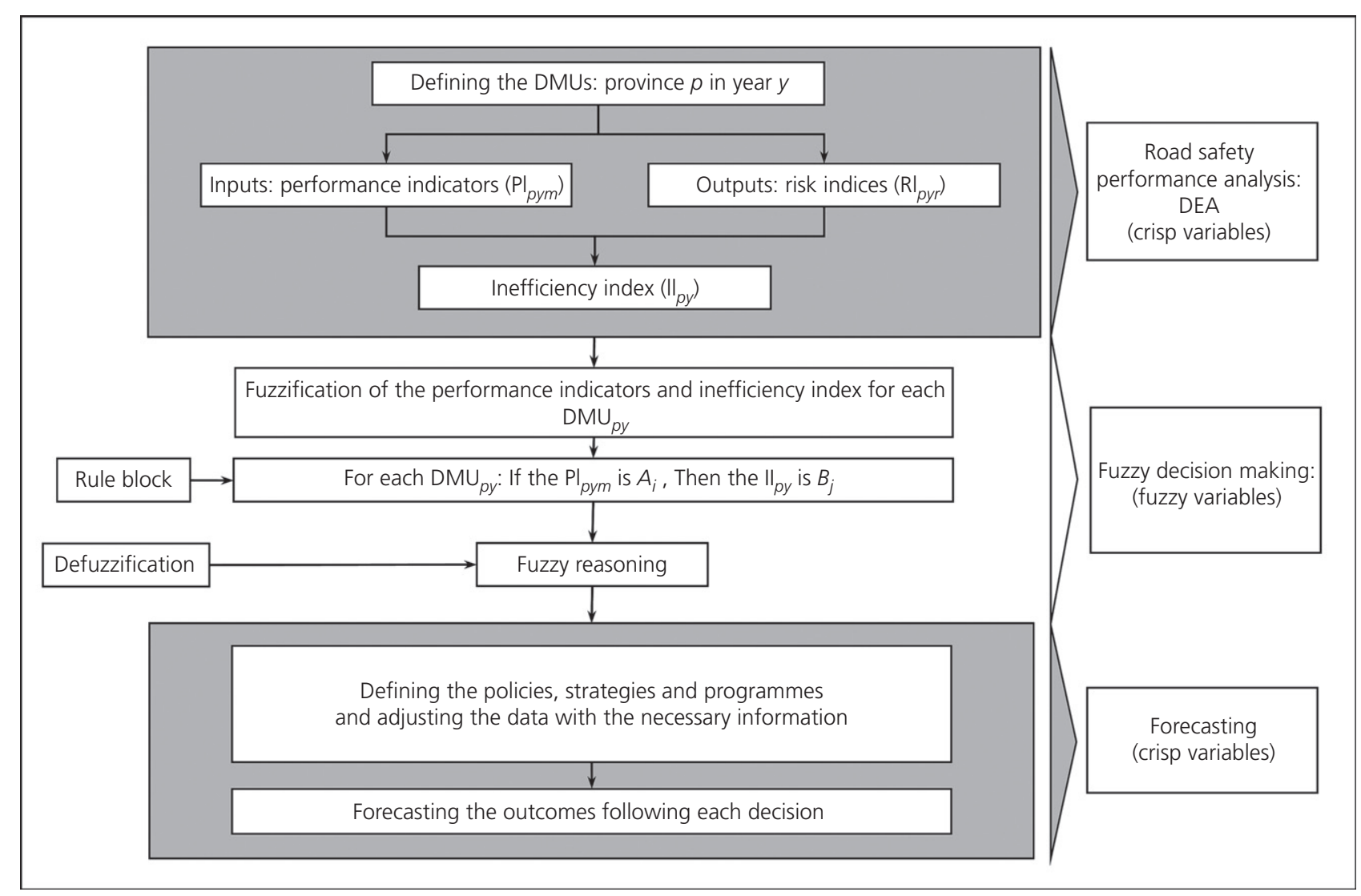

Figure 1. Concept of procedure for performance evaluation and planning for road safety measures

efforts in road safety measures maximises road safety performance given its current road safety situation.

This conceptual model is illustrated in Figure 1 and contains three major parts: (a) DEA-based road safety performance evaluation, (b) the creation of the fuzzy decision-making system and $(c)$ the formulation of new targets for a region based on its current road safety situation and what-if analyses carried out on the rule-based system. The whole analysis process stands on these three main steps and the output of each is applied as the input of the next step. In a little more detail, the three steps are as follows.

(a) A DEA-based road safety performance efficiency evaluation for each region. In this study, 30 different regions (DMUs) in Iran were considered. For each region, 2 years of input and output data were available for a predefined set of road safety indicators.

(b) The generation of a set of decision rules derived from the efficiency calculation for each DMU carried out in the previous step. More specifically, a fuzzy reasoning approach is adopted to derive the decision rules, identify the degrees of satisfaction, interpret the fuzzy results and finally convert them back into numerical crisp outputs. (c) The final step involves defining the policies, strategies and programmes, adjusting the data with the necessary information and finally forecasting the outcomes following each decision.

The following sections now describe each step in more detail.

\subsection{Data envelopment analysis}

In the first step, using the DEA method, a relative inefficiency index is calculated for each province in each year. The inefficiency index is the one that is achieved according to the preexperienced measures implemented throughout the provinces in Iran. Each province in each year is defined as a DMU in the DEA. The inefficiency index is defined as the proportion of the weighted sum of outputs (fatality risks) to the weighted sum of inputs (performance indicators), given by

$$
\text { 1. } \mathrm{II}=\frac{\sum_{r=1}^{2} \mathrm{WFI}_{r}}{\sum_{i=1}^{6} \mathrm{WPI}_{i}}
$$

As already mentioned, the inputs to the DEA are defined as a set of road safety measures for the different provinces in Iran for 2 years; these represent the RSPIs. As for the output of the 
DEA, two risk indicators are included - the number of fatalities per million vkm travelled and the number of fatalities per $100 \mathrm{~km}$ of road. As noted earlier, these two types of risk refer to all types of road in a region as well as the traffic demand, which includes the total number of vkm travelled. Technically, the DEA model can be written as the following linear optimisation model.

2. $\operatorname{Min} \theta=u_{1} y_{1}+u_{2} y_{2}=\sum_{r=1}^{2} u_{r} y_{r}$

Subject to

3. $\sum_{i=1}^{6} v_{i} x_{i}=1$

4. $\quad \sum_{r=1}^{2} u_{r} y_{r j}-\sum_{i=1}^{6} v_{i} x_{i j} \geq 0 \quad(j=1,2, \ldots, 60)$

$v_{i}, u_{r} \geq 0$

The variable $y_{r}$ in Equation 2 represents the outputs (i.e. fatality risk). Equation 2 shows the objective function (i.e. the inefficiency rate $\theta$ to be minimised). The model implies that the inefficiency lies at a minimum rate of 1 . As a result, the weighted outputs will always be greater than or equal to the weighted inputs, as displayed in Equation 4. Using the dual model for this linear programming model, a target-setting exercise can be carried out using the extracted dual prices from this model. In fact, the dual model can be written as follows.

\section{5. $\operatorname{Max} \omega_{0}$}

Subject to

6. $\sum_{j=1}^{60} y_{r j} \lambda_{j} \leq y_{r} \quad(r=1,2)$

7. $x_{i} \omega_{0}-\sum_{j=1}^{60} x_{i j} \lambda_{j} \leq 0 \quad(i=1, \ldots, 6)$

$\omega_{0}, \lambda_{j} \geq 0$
In these equations $\omega_{0}$ is the objective value to be maximised in the dual model. The decision variable $\lambda_{j}$ represents the dual price for the $j$ th DMU under study so that the values $\lambda_{j} \neq 0$ reveal the applicable dual prices for benchmark units. Finally, the target actions with the corresponding values for the different RSPIs in inefficient provinces can be calculated as (see Hermans et al., 2009)

8. Target $_{i, A}=\sum_{b=1}^{B}\left(\frac{\lambda_{b}}{I I_{A}} \times x_{i, b}\right)$

Provided that the target is achieved, the inefficiency rate can be minimised as far as it equals 1 . Having identified the targets, the required changes in input values are determined.

\subsection{Fuzzy decision-making}

The second step in Figure 1 establishes the rules and incorporates fuzzy hypotheses based on the fuzzy variables through which the degree of satisfaction (DoS) for the rules adopted from experienced performances can be calculated. Each fuzzy rule includes a premise (the phrase after 'If') and a conclusion (the phrase after 'Then').

Here, seven explanatory levels are introduced to state linguistically the performance characteristics as well as the inefficiency values: very low, low, almost low, medium, almost high, high and very high. The structure of the membership functions is a primary issue of concern. In this study, trapezoidal membership functions are adopted by a $k$-means data clustering technique to classify these seven linguistic levels. The typical fuzzification method used in this study is discussed in the next section.

The fuzzy rules are established by explaining the efficiency level as a consequence of safety measures implemented in each province. The efficiency level inherently encompasses and reflects the safety level. The linguistic values of inputs (road safety measures) constitute the premise (phrases after 'If') while the linguistic values of the inefficiency rate form the consequence (phrases after 'Then') of the fuzzy rules.

Hence, each fuzzy rule as a hypothesis $H_{i}$ is defined in a seven-dimensional set of $u_{1} \times u_{2} \times \ldots \times u_{6} \times V$ in which $u_{1}, \ldots, u_{6}$ are the reference sets for the premises and $V$ is the one for conclusions. The variable set $R(u, v)$ is a compound set of the premises and conclusions whose members are calculated by the fuzzy values $\mu_{\tilde{A}}(u)$ and $\mu_{\tilde{B}}(v)$ using the following equation.

9. $R\left(u_{1}, \ldots, u_{6}, V\right)=\mu_{\tilde{A}_{1}}\left(u_{1}\right) \times \ldots \times \mu_{\tilde{A}_{2}}\left(u_{6}\right) \times \mu_{\tilde{B}}(v)$

Since each of the reference sets $u_{1}, \ldots, u_{6}$ and $V$ includes seven verbal values, there will be $7^{7}(823543)$ hypotheses included in 
the master set $R$, known as the fuzzy rule block. By combining the values of each hypothesis in a set of training units (a total of 120 units in this study - 60 main DEA units (DMUs) plus 60 targeted units attributed to the main DEA units by the benchmarking and target-setting process), the DoS for each of the rules in the rule block can be calculated. In other words, the DoS for each rule in the rule block can be estimated by calculating the mathematical average of all samples, as given by

$$
\text { 10. } \operatorname{DoS}_{h}=\frac{\sum_{i}^{120} \mu_{h}\left(x_{i}\right)}{120}
$$

Indeed, the sum of all DoS values for all rules will equal $1 \cdot 0$, meaning that

$$
\text { 11. } \sum_{h=1}^{823543} \operatorname{DoS}_{h}=1
$$

Finally, once the rule block is established, it is completed by the fuzzy hypothesis test having calculated the DoS for each fuzzy rule.

The fuzzy reasoning process can be constructed on the basis of a fuzzy logical inference system. The rule block, known as the rule base in an FDSS, represents a distinct knowledge base for a given set of training samples. In this study, the fuzzy reasoning process consists of Iranian provinces' experiences over 2 years. The applied direct methodology to fulfil the fuzzy reasoning process with the rules incorporating six inputs and one output can be expressed as

$$
\forall i \text { : If } x_{i} \text { is } A_{i} \text {, Then } y \text { is } B
$$

in which, for $i=1,2, \ldots, 6, x_{1}$ is police operations, $x_{2}$ is treated black spots, $x_{3}$ is the amount of freeways and highways, $x_{4}$ is speed cameras, $x_{5}$ is emergency medical services stations, $x_{6}$ is road lighting projects and $y$ is the inefficiency value.

The term $A_{i}$ involves the fuzzy sets that state the verbal characteristics of the above six variables by means of fuzzy membership functions. Fuzzy reasoning by the direct method to determine the inefficiency value considering the training knowledge base can then proceed as follows.

Step 1. Having distinct crisp values of $\alpha_{i}$ for each RSPI, the premise adjustment is measured as the generalised form

$$
\text { 12. } w=\mu_{A 1}\left(\alpha_{1}\right) \wedge \mu_{A 2}\left(\alpha_{2}\right) \wedge \ldots \wedge \mu_{A 6}\left(\alpha_{6}\right)
$$

In this equation, the operator $\wedge$ represents the 'Min' action exerted on the membership values $\mu_{A i}\left(\alpha_{i}\right)$.
- Step 2. Using the adjusted $w$ value for each rule, the area under the membership function of the conclusion is estimated as

$$
\text { 13. } \mu_{B}(\beta)=W \times \mu(\beta)
$$

where the function $\mu(\beta)$ is the adjusted value of the conclusion function for the related rule. Thereby, the conclusion's membership function is cut to find the same height as the least value of the premise.

- Step 3. Cumulating all rules with the two previous steps exerted, the maximum value among the conclusions of all rules can be found by the $\vee$ operator. The result is the final fuzzy response and is written as the generalised form

$$
\text { 14. } \mu_{B}(\beta)=\mu_{B}^{(1)}(\beta) \vee \mu_{B}^{(2)}(\beta) \vee \ldots \vee \mu(\beta)_{B}^{(k)}
$$

in which the phrase $\mu_{B}^{(j)}(\beta)$ reflects the concluded fuzzy value of rule $j$ and parameter $k$ is the total number of rules in the rule block.

Having determined the final result, $\mu_{B}(\beta)$, the reasoning process is completed. But it is still necessary to convert the fuzzy value of the result back to a numerical crisp form. The conversion action known as 'defuzzification' is usually performed by the centroid method (Azar and Faraji, 2008; Harris, 2006; Ross, 2004). The result of the defuzzification task is a numerical distinct inefficiency value in the same nature of the relative inefficiency values earned by the DEA process.

\subsection{Forecasting the outcomes}

The above-mentioned stages form an FDSS that can be used to improve the applied decision making in planning road safety measures. This application enables road safety planners to define a variety of strategies, considering the inventories and limitations attributed by the road safety measures in each region of the country, and finally to depict a perspective of their efficiency. Then, calculating the inefficiency values corresponding to the defined strategies of the limited resources, it is possible to select the best alternative with the lowest inefficiency.

\section{Results and discussion}

This study covered road safety performance data and fatality risk indices available in all provinces of Iran (30 provinces) for a period of 2 years (2010 and 2011). All data regarding the RSPIs (i.e. the indices referring to the countermeasures) were taken from annual reports published by the Road Maintenance and Transportation Organization of Iran (RMTO, 2010, 2011). Data representing fatality rates were taken from the Road Safety Commission of the Ministry of Road and Transportation (RSC, 2010, 2011). 
Target value

\begin{tabular}{|c|c|c|c|c|c|c|c|c|c|c|c|c|c|c|c|c|}
\hline \multirow[b]{2}{*}{ Province } & \multirow[b]{2}{*}{ DMU } & \multicolumn{9}{|c|}{ Existing value } & \multicolumn{6}{|c|}{ Target value } \\
\hline & & PO & BS & $\mathrm{H} \& \mathrm{~F}$ & SCC & EMS & Li & FR1 & FR2 & Ineff & PO & BS & $\mathrm{H} \& \mathrm{~F}$ & SCC & EMS & $\mathrm{Li}$ \\
\hline \multicolumn{17}{|l|}{ Year 2010} \\
\hline Azerbaijan-E & 1 & 0.32 & 1.90 & 27.79 & 0.00 & 1.45 & $2 \cdot 68$ & 0.805 & $16 \cdot 6$ & $1 \cdot 279$ & 0.32 & 1.89 & 31.86 & $3 \cdot 19$ & 1.83 & 5.01 \\
\hline Azerbaijan-W & 2 & 0.26 & $1 \cdot 39$ & 7.53 & 0.00 & 0.84 & $2 \cdot 67$ & $1 \cdot 228$ & $18 \cdot 2$ & 1.974 & 0.26 & $1 \cdot 39$ & $17 \cdot 12$ & $1 \cdot 35$ & $1 \cdot 27$ & $5 \cdot 20$ \\
\hline Ardebil & 3 & 0.37 & $1 \cdot 05$ & 11.01 & 0.00 & 1.57 & 9.86 & 0.980 & $12 \cdot 7$ & 1.000 & 0.37 & 1.05 & 11.01 & 0.00 & 1.57 & 9.86 \\
\hline Isfahan & 4 & 0.28 & $1 \cdot 47$ & $60 \cdot 57$ & 1.62 & 1.44 & $2 \cdot 13$ & 0.587 & $16 \cdot 9$ & $1 \cdot 105$ & 0.29 & 1.50 & $61 \cdot 43$ & 1.64 & 1.54 & 3.32 \\
\hline Ilam & 5 & 0.28 & 0.35 & 3.05 & 0.00 & $1 \cdot 40$ & 0.14 & 1.531 & 8.9 & 1.000 & 0.28 & 0.35 & 3.05 & 0.00 & 1.40 & 0.14 \\
\hline Booshehr & 6 & $0 \cdot 30$ & 0.66 & $43 \cdot 33$ & 0.00 & $1 \cdot 79$ & $2 \cdot 80$ & 0.697 & $11 \cdot 3$ & 1.000 & $0 \cdot 30$ & 0.66 & 43.33 & 0.00 & 1.79 & $2 \cdot 80$ \\
\hline Tehran & 7 & 1.06 & 0.76 & $83 \cdot 40$ & 9.80 & $5 \cdot 32$ & 18.98 & 0.430 & $70 \cdot 0$ & 1.079 & $1 \cdot 13$ & 4.82 & $96 \cdot 35$ & 9.80 & $6 \cdot 23$ & 22.04 \\
\hline Chaharmahal & 8 & 0.28 & 1.59 & $4 \cdot 28$ & 0.00 & 1.59 & 3.53 & 1.519 & $10 \cdot 8$ & $1 \cdot 131$ & 0.28 & $1 \cdot 62$ & $6 \cdot 70$ & 0.00 & 1.60 & 3.57 \\
\hline Khorasan-S & 9 & $0 \cdot 10$ & $0 \cdot 18$ & 0.66 & 0.00 & 0.86 & $1 \cdot 40$ & $1 \cdot 409$ & $4 \cdot 7$ & $1 \cdot 088$ & $0 \cdot 10$ & 0.52 & 2.08 & 0.00 & 0.86 & $1 \cdot 37$ \\
\hline Khorasan-Raz & 10 & 0.29 & 1.03 & $24 \cdot 48$ & 0.00 & 1.59 & $2 \cdot 78$ & 0.772 & $16 \cdot 9$ & $1 \cdot 452$ & 0.29 & 1.02 & 31.49 & $3 \cdot 32$ & 1.68 & 3.82 \\
\hline Khorasan-N & 11 & 0.36 & $1 \cdot 25$ & $12 \cdot 84$ & 0.00 & $1 \cdot 16$ & 4.55 & 1.823 & $16 \cdot 2$ & $1 \cdot 341$ & 0.36 & $1 \cdot 28$ & 13.00 & 0.71 & 1.74 & 4.59 \\
\hline Khoozestan & 12 & 0.23 & 1.65 & $31 \cdot 23$ & 0.00 & 1.74 & 1.67 & 0.518 & 17.6 & 1.236 & $0 \cdot 30$ & 1.64 & $32 \cdot 28$ & 3.69 & 1.74 & $4 \cdot 20$ \\
\hline Zanjan & 13 & 0.43 & $2 \cdot 80$ & 41.83 & 0.00 & $2 \cdot 01$ & $4 \cdot 24$ & $2 \cdot 130$ & 21.9 & $1 \cdot 369$ & 0.43 & $2 \cdot 78$ & $41 \cdot 78$ & 0.00 & $2 \cdot 34$ & $5 \cdot 44$ \\
\hline Semnan & 14 & 0.54 & $1 \cdot 14$ & $60 \cdot 59$ & 0.00 & 2.08 & 5.65 & $1 \cdot 176$ & $22 \cdot 5$ & 1.093 & 0.54 & 1.42 & $60 \cdot 41$ & 5.58 & 3.03 & 6.02 \\
\hline Sistan & 15 & 0.16 & 0.41 & 0.66 & 0.00 & 1.08 & 0.45 & $1 \cdot 376$ & $11 \cdot 2$ & 1.933 & 0.16 & 1.07 & $7 \cdot 36$ & 0.29 & 1.08 & 1.87 \\
\hline Fars & 16 & 0.23 & $2 \cdot 01$ & $14 \cdot 70$ & 0.00 & 1.48 & 1.85 & $1 \cdot 206$ & 17.6 & 1.819 & 0.26 & $2 \cdot 02$ & $22 \cdot 95$ & $2 \cdot 11$ & 1.49 & $4 \cdot 13$ \\
\hline Ghazvin & 17 & 0.49 & $3 \cdot 13$ & $65 \cdot 27$ & 6.43 & 1.98 & 8.08 & 2.005 & 35.8 & 1.590 & 0.64 & 4.77 & 72.99 & $7 \cdot 88$ & 3.66 & 8.35 \\
\hline Ghom & 18 & 0.67 & 3.03 & $102 \cdot 77$ & $12 \cdot 73$ & $2 \cdot 69$ & $14 \cdot 12$ & 1.335 & $41 \cdot 8$ & 1.004 & 0.68 & 5.05 & 103.95 & $12 \cdot 85$ & $3 \cdot 10$ & $14 \cdot 30$ \\
\hline Kurdistan & 19 & 0.25 & $2 \cdot 46$ & $4 \cdot 70$ & 0.00 & $1 \cdot 20$ & 2.84 & 2.063 & $25 \cdot 4$ & 2.809 & 0.25 & $2 \cdot 47$ & $9 \cdot 47$ & 0.19 & $1 \cdot 20$ & $6 \cdot 10$ \\
\hline Kerman & 20 & $0 \cdot 20$ & $2 \cdot 50$ & 19.97 & 0.00 & $1 \cdot 54$ & 0.72 & 0.960 & $13 \cdot 2$ & $1 \cdot 293$ & 0.27 & $2 \cdot 49$ & $21 \cdot 32$ & $1 \cdot 80$ & 1.54 & 4.63 \\
\hline Kermanshah & 21 & 0.38 & 0.63 & $18 \cdot 50$ & 0.00 & 0.79 & $5 \cdot 60$ & $1 \cdot 367$ & 14.9 & $1 \cdot 151$ & 0.38 & 0.92 & 18.41 & 1.29 & 1.83 & 6.09 \\
\hline Kohgiluyeh & 22 & 0.27 & 0.82 & $2 \cdot 33$ & 0.00 & $2 \cdot 01$ & $2 \cdot 19$ & 2.337 & $10 \cdot 1$ & 1.052 & 0.27 & 1.82 & 4.65 & 0.00 & $2 \cdot 01$ & 2.55 \\
\hline Golestan & 23 & 0.36 & $2 \cdot 63$ & $21 \cdot 43$ & 0.00 & $2 \cdot 63$ & 13.95 & 1.569 & 31.9 & $1 \cdot 375$ & 0.57 & $2 \cdot 63$ & $26 \cdot 25$ & $1 \cdot 39$ & $2 \cdot 62$ & 13.90 \\
\hline Gilan & 24 & 0.48 & $2 \cdot 55$ & $30 \cdot 63$ & 0.00 & $1 \cdot 78$ & 7.96 & 1.896 & $37 \cdot 3$ & 1.980 & 0.47 & $2 \cdot 56$ & 43.01 & $4 \cdot 15$ & $2 \cdot 60$ & 7.94 \\
\hline Lorestan & 25 & 0.43 & 1.66 & $15 \cdot 65$ & 0.00 & $2 \cdot 96$ & 4.99 & $2 \cdot 120$ & $30 \cdot 1$ & $1 \cdot 702$ & 0.48 & 1.84 & $48 \cdot 80$ & 4.90 & $2 \cdot 96$ & $5 \cdot 64$ \\
\hline Mazandaran & 26 & 0.49 & $3 \cdot 26$ & $31 \cdot 22$ & 0.00 & $2 \cdot 24$ & $11 \cdot 19$ & $1 \cdot 325$ & 28.5 & $1 \cdot 389$ & 0.49 & $3 \cdot 25$ & $31 \cdot 25$ & $1 \cdot 26$ & $2 \cdot 35$ & $11 \cdot 18$ \\
\hline Markazi & 27 & 0.42 & 1.48 & 34.76 & $2 \cdot 89$ & $1 \cdot 37$ & 3.96 & 0.986 & 19.4 & $1 \cdot 184$ & 0.42 & 1.49 & $47 \cdot 46$ & 5.03 & $2 \cdot 49$ & $5 \cdot 41$ \\
\hline Hormozgan & 28 & 0.17 & 0.20 & 14.92 & 0.00 & 0.99 & 0.72 & 0.265 & $12 \cdot 2$ & 1.445 & 0.17 & 0.58 & $17 \cdot 10$ & $1 \cdot 76$ & 0.99 & 2.86 \\
\hline Hamedan & 29 & $0 \cdot 30$ & $1 \cdot 14$ & $44 \cdot 14$ & 0.00 & $1 \cdot 50$ & $2 \cdot 58$ & $1 \cdot 650$ & $28 \cdot 2$ & $2 \cdot 402$ & $0 \cdot 30$ & $1 \cdot 13$ & 43.83 & 0.24 & 1.75 & $3 \cdot 13$ \\
\hline Yazd & 30 & 0.21 & 0.31 & 19.63 & 0.00 & 0.82 & 1.47 & 0.433 & $7 \cdot 6$ & 1.000 & 0.21 & 0.31 & 19.63 & 0.00 & 0.82 & 1.47 \\
\hline \multicolumn{17}{|l|}{ Year 2011} \\
\hline Azerbaijan-E & 31 & 0.32 & $1 \cdot 23$ & 27.93 & 0.00 & 1.65 & 3.85 & 0.771 & $16 \cdot 7$ & $1 \cdot 284$ & 0.32 & $1 \cdot 25$ & 35.06 & 3.68 & 1.89 & $4 \cdot 40$ \\
\hline Azerbaijan-W & 32 & 0.26 & $3 \cdot 18$ & 8.83 & 0.00 & $1 \cdot 20$ & $2 \cdot 66$ & $1 \cdot 197$ & $18 \cdot 0$ & 1.878 & 0.26 & $3 \cdot 19$ & $17 \cdot 29$ & $1 \cdot 30$ & 1.29 & $5 \cdot 41$ \\
\hline Ardebil & 33 & 0.37 & $7 \cdot 32$ & $12 \cdot 78$ & 0.00 & 1.64 & $10 \cdot 23$ & 1.031 & $14 \cdot 1$ & 1.000 & 0.37 & $7 \cdot 32$ & $12 \cdot 78$ & 0.00 & 1.64 & $10 \cdot 23$ \\
\hline Isfahan & 34 & 0.28 & 1.54 & $72 \cdot 60$ & $1 \cdot 25$ & 1.46 & 2.93 & 0.547 & $16 \cdot 8$ & 1.000 & 0.28 & 1.54 & $72 \cdot 60$ & $1 \cdot 25$ & 1.46 & 2.93 \\
\hline \|lam & 35 & 0.28 & $2 \cdot 71$ & 3.29 & 0.00 & 1.39 & 0.76 & 1.921 & 11.5 & $1 \cdot 195$ & 0.28 & 2.69 & 5.97 & 0.00 & $1 \cdot 38$ & 3.59 \\
\hline Booshehr & 36 & 0.29 & 2.92 & 48.96 & 0.65 & 1.75 & 4.09 & 0.669 & $12 \cdot 7$ & 1.000 & 0.29 & 2.92 & 48.96 & 0.65 & 1.75 & 4.09 \\
\hline Tehran & 37 & 1.05 & 3.84 & 88.29 & 8.66 & 5.79 & 20.92 & 0.338 & $60 \cdot 0$ & 1.000 & 1.05 & 3.84 & $88 \cdot 29$ & 8.66 & 5.79 & $20 \cdot 92$ \\
\hline Chaharmahal & 38 & 0.26 & $2 \cdot 07$ & 9.42 & 0.00 & 1.81 & $3 \cdot 36$ & $1 \cdot 209$ & $9 \cdot 3$ & 1.000 & 0.26 & $2 \cdot 07$ & $9 \cdot 42$ & 0.00 & 1.81 & $3 \cdot 36$ \\
\hline Khorasan-S & 39 & $0 \cdot 10$ & 0.31 & 0.90 & 0.00 & 0.96 & $1 \cdot 40$ & 1.456 & 4.7 & 1.000 & $0 \cdot 10$ & 0.31 & 0.90 & 0.00 & 0.96 & 1.40 \\
\hline Khorasan-Raz & 40 & 0.28 & 0.93 & $26 \cdot 26$ & 0.00 & 1.59 & $2 \cdot 84$ & 0.750 & $17 \cdot 1$ & 1.486 & 0.28 & 0.92 & 31.04 & 3.29 & 1.65 & 3.72 \\
\hline Khorasan-N & 41 & 0.36 & 3.57 & $15 \cdot 78$ & 0.00 & 1.34 & 4.83 & $2 \cdot 210$ & $23 \cdot 0$ & $1 \cdot 800$ & 0.36 & 3.59 & $15 \cdot 79$ & 0.93 & 1.75 & $5 \cdot 76$ \\
\hline Khoozestan & 42 & 0.23 & 3.49 & 32.55 & 0.00 & 1.78 & $3 \cdot 26$ & 0.532 & $17 \cdot 4$ & 1.096 & 0.31 & $3 \cdot 50$ & $36 \cdot 39$ & 4.94 & 1.80 & 3.33 \\
\hline Zanjan & 43 & 0.43 & 2.95 & 43.92 & 4.29 & $2 \cdot 30$ & $4 \cdot 24$ & 1.971 & $21 \cdot 4$ & $1 \cdot 313$ & 0.43 & 2.96 & 44.04 & $4 \cdot 30$ & $2 \cdot 44$ & $6 \cdot 40$ \\
\hline Semnan & 44 & 0.60 & $2 \cdot 78$ & $76 \cdot 71$ & 0.00 & $2 \cdot 63$ & $7 \cdot 51$ & $1 \cdot 152$ & $24 \cdot 1$ & 1.000 & 0.60 & $2 \cdot 78$ & $76 \cdot 71$ & 0.00 & $2 \cdot 63$ & $7 \cdot 51$ \\
\hline
\end{tabular}




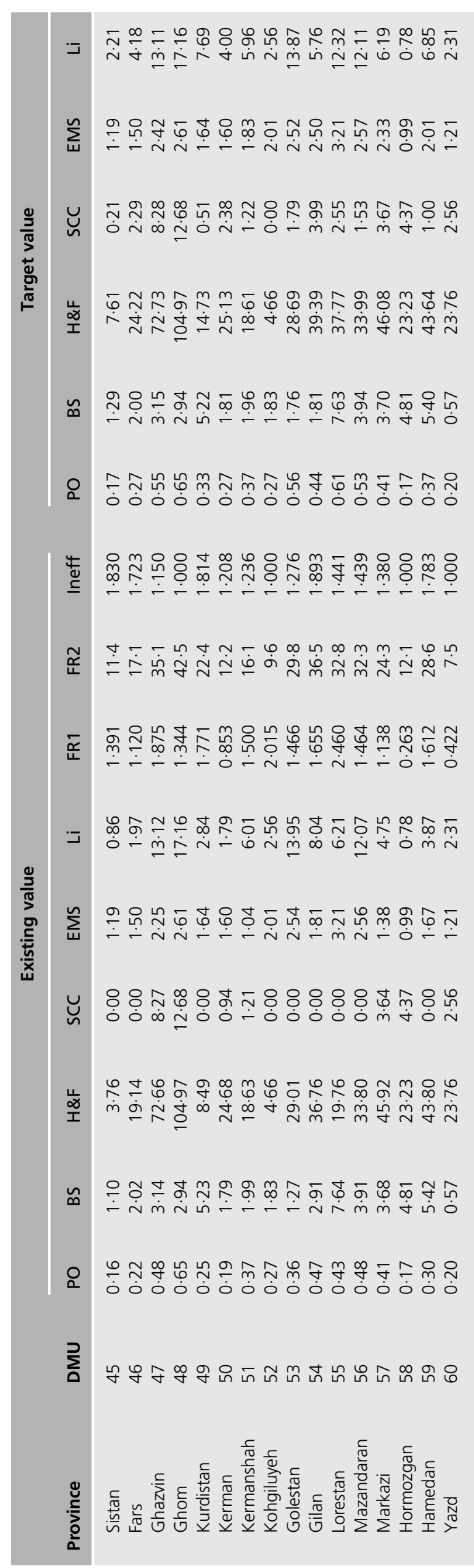

\subsection{DEA results}

Once the DEA process and target setting was carried out for all units under study, an inefficiency value larger than or equal to 1 was obtained for each province. Inefficient entities will obtain a higher inefficiency score due to their worse performance. Table 1 shows the DEA input and output values. The values of the RSPIs (DEA inputs) for the two years of the study are given. These indicators include measures related to police operations, removed black spots, highways and freeways, speed control cameras, emergency medical services and lighting facilities; the definition of each indicator is given in Section 2. Columns FR1 and FR2 show the values of the risk indices (DEA outputs): FR1 represents the fatality rate per vkm driven while FR2 refers to the fatality rate per $100 \mathrm{~km}$ of road in each province. The column labelled 'Ineff' shows the calculated inefficiency value for each province as given by the DEA. Finally, the last six columns of Table 1 show the target values provided by the DEA model for each of the performance indicators.

\subsection{Data fuzzification}

In this step, the inefficiency values calculated by the DEA process are entered as the conclusions or output variables of the rule block in the fuzzy reasoning stage. Beforehand, all data containing RSPIs as the inputs and inefficiency rates as the outputs of the rule block should be converted to the verbal variables which define the fuzzy membership functions.

The membership functions that build up the explanatory composition of the data are made up of trapezoidal functions. A $k$-means clustering $(k=7)$ was carried out such that the seven mean values were precisely identified for each input or output variable. Then, distances of data from the attributed cluster centres were recorded so as to be reclassified into two groups consisting of near data and far data from cluster centres. In this way, near data are located on the upper side of the trapezoidal and far data on the sloped legs. The results are shown in Table 2. Figure 2 shows the trapezoidal or triangular membership functions of the variables used in the fuzzy analysis.

\subsection{Rule block and FDSS}

It was previously shown that the combination of all possible fuzzy categories for the seven variables (six antecedents + one consequent) results in a rule block of 823543 rules $\left(7^{7}\right)$. For each of these rules in the rule block, the DoS needs to be established based on the data from 30 provinces over 2 years as well as the optimal targets attributed. The DoS value for each rule is calculated by averaging the product of fuzzy membership values of input and output measures (see Equations 10 and 11). For example, DMU 60 (Yazd in year 2011) gives PO as $100 \%$ low (L), BS as $100 \%$ very low (VL), H\&F as $61 \%$ low (L), SCC as $61 \%$ low (L), EMS as $100 \%$ very low (VL), Li as $57 \%$ low (L) and Ineff as $100 \%$ very low (VL). Therefore the 
Table 2. Data clustering for input and output indices

\begin{tabular}{|c|c|c|c|c|c|c|c|c|}
\hline \multirow[b]{2}{*}{ Cluster } & & \multicolumn{6}{|c|}{ Input indices } & \multirow{2}{*}{$\begin{array}{l}\text { Output } \\
\text { Ineff }\end{array}$} \\
\hline & & PO & BS & $\mathrm{H} \& \mathrm{~F}$ & SCC & EMS & $\mathrm{Li}$ & \\
\hline 1 & Mean & $0 \cdot 10$ & 0.47 & $5 \cdot 42$ & 0.05 & 1.04 & $1 \cdot 28$ & 1.008 \\
\hline Very low (VL) & Near data & $0 \cdot 10$ & $0.18-0.66$ & $0.66-8.49$ & $0-0.29$ & $0 \cdot 79-1 \cdot 27$ & $0.14-1.97$ & $1.00-1.05$ \\
\hline 2 & Mean & $0 \cdot 19$ & $1 \cdot 21$ & $18 \cdot 55$ & 1.62 & 1.52 & 3.46 & 1.23 \\
\hline Low (L) & Near data & $0 \cdot 17-0.21$ & $1 \cdot 02-1 \cdot 39$ & $15 \cdot 65-21 \cdot 43$ & $1 \cdot 29-1 \cdot 80$ & $1 \cdot 29-1 \cdot 68$ & $2 \cdot 55-4 \cdot 20$ & $1 \cdot 24-1 \cdot 29$ \\
\hline 3 & Mean & 0.28 & 1.83 & $30 \cdot 87$ & $3 \cdot 77$ & 1.86 & $6 \cdot 39$ & 1.41 \\
\hline Almost low (AL) & Near data & $0 \cdot 26-0 \cdot 30$ & $1 \cdot 64-2 \cdot 02$ & $27 \cdot 79-33 \cdot 80$ & $3 \cdot 64-3.99$ & $1.74-2 \cdot 08$ & $5 \cdot 60-6 \cdot 85$ & $1 \cdot 38-1.45$ \\
\hline 4 & Mean & 0.39 & $2 \cdot 76$ & $44 \cdot 21$ & $5 \cdot 38$ & $2 \cdot 49$ & $10 \cdot 84$ & 1.67 \\
\hline Medium (M) & Near data & $0 \cdot 37-0.41$ & $2 \cdot 56-2 \cdot 96$ & $41 \cdot 78-47 \cdot 46$ & $5 \cdot 58$ & $2 \cdot 24-2 \cdot 69$ & $10 \cdot 23-11 \cdot 19$ & $1 \cdot 70$ \\
\hline 5 & Mean & 0.51 & 3.51 & $67 \cdot 19$ & $8 \cdot 35$ & $3 \cdot 16$ & $13 \cdot 63$ & $1 \cdot 87$ \\
\hline Almost high $(\mathrm{AH})$ & Near data & $0.49-0.53$ & $3 \cdot 49-3 \cdot 70$ & $65 \cdot 27$ & $7 \cdot 88-8 \cdot 66$ & $2 \cdot 96-3 \cdot 21$ & $13 \cdot 11-14 \cdot 30$ & $1.83-1.89$ \\
\hline 6 & Mean & 0.64 & $5 \cdot 06$ & $82 \cdot 68$ & $9 \cdot 80$ & $5 \cdot 32$ & $17 \cdot 77$ & $2 \cdot 40$ \\
\hline High $(\mathrm{H})$ & Near data & $0.64-0.65$ & $5 \cdot 05-5 \cdot 23$ & $83 \cdot 40$ & $9 \cdot 80$ & $5 \cdot 32$ & $17 \cdot 16$ & $2 \cdot 40$ \\
\hline 7 & Mean & 1.05 & $7 \cdot 48$ & $102 \cdot 6$ & $12 \cdot 74$ & 5.94 & $21 \cdot 29$ & $2 \cdot 81$ \\
\hline Very high (VH) & Near data & $1 \cdot 05-1 \cdot 13$ & $7 \cdot 32-7 \cdot 64$ & $102 \cdot 77-104 \cdot 97$ & $12 \cdot 68-12 \cdot 85$ & $5 \cdot 79-6 \cdot 23$ & $20 \cdot 92-22 \cdot 04$ & $2 \cdot 81$ \\
\hline
\end{tabular}

individual DoS for the rule

$$
\text { If } \begin{aligned}
\mathrm{PO} & =\mathrm{L} \& \mathrm{BS}=\mathrm{VL} \& \mathrm{H} \& \mathrm{~F}=\mathrm{L} \& S C C \\
& =\mathrm{L} \& \mathrm{EMS}=\mathrm{VL} \& \mathrm{Li}=\mathrm{L} \quad \text { Then Ineff }=\mathrm{VL}
\end{aligned}
$$

supported by DMU 60 is calculated as $1 \times 1 \times 0.61 \times 0.61 \times$ $1 \times 0 \cdot 57 \times 1$, which equals $0 \cdot 212$. Such a calculation for the same rule in other units will result in an individual DoS value and the total DoS is calculated by averaging them.

Note that only a part of the rules with a relatively higher DoS value will represent the dominant condition throughout 120 units so that they can be accepted as effective rules. Recall that the targeted units obtained by the benchmarking process show the exact outcomes; in total 120 units can be applied that consist of 60 main DEA units (30 provinces in 2 years) plus 60 targeted units attributed to those 60 main DEA units.

Among all the rules considered in the rule block, many have very small DoS values close to zero. Therefore, in order to simplify the analysis, the rule block can be modified by neglecting the rules with very small DoS values. A part of the modified rule block with 285 effective rules is shown in Table 3. The rules with a DoS of 0.001 or higher were retained and inserted in the modified rule block. The fuzzy reasoning procedure is the last stage in running the fuzzy decision-making system.

\subsection{Discussion}

A critical use of the FDSS made up of the established fuzzy reasoning system is the numerical analysis of decision-making using numerical inputs (RSPIs) that are followed by numerical outputs (inefficiency indices). By doing so, one can analyse all six input indices against the inefficiency index at the same time.

An example of the analysis can best illustrate the decisionmaking process. To this end, a region is assumed to have a relatively high rate of freeway facilities but with low rates of various managerial road safety measures such as speed cameras and lighting equipment. Therefore, suppose $\mathrm{PO}=0 \cdot 26, \mathrm{BS}=0 \cdot 97, \mathrm{H} \& \mathrm{~F}=68 \cdot 11, \mathrm{SCC}=1 \cdot 06, \mathrm{EMS}=1 \cdot 50$ and $\mathrm{Li}=1 \cdot 54$. An inefficiency rate can now be estimated based on the developed fuzzy reasoning system both for the current situation and for alternative scenarios (i.e. other combinations of safety performance indicator values that are considered as feasible to achieve by policy makers based on available investment budgets). Table 4 shows four alternative strategies defined by a road agency based on the available investment budget. Table 5 illustrates the fuzzy reasoning and defuzzification process for the measures defined in the existing situation (i.e. 'do nothing' strategy) that is described in the first row of Table 4. The same process can be done for the other three strategies so that a distinct numerical value of inefficiency can be calculated for each of them. By defining the rule block (Table 3) in a software application, the inefficiency rates were easily estimated as $1 \cdot 1453,1 \cdot 0260,1 \cdot 2600$ and 1.5578 for strategies 0 to 3 respectively. As the final decision point, due to its lowest inefficiency rate, strategy 1 can be selected as the best feasible alternative. This strategy implies mere concentration on road lighting facilities.

In order to determine the authenticity of the results, the estimated fuzzy system-based results can be compared with the actual DEA-based inefficiency rates through a correlation analysis. Table 6 shows both actual and predicted values of the inefficiency rates for the 60 DMUs and Figure 3 illustrates how close the results are. This comparison analysis resulted in a correlation factor $\left(R^{2}\right)$ of $94 \%$, which shows a high acceptability of the fuzzy system created by seven qualitative terms in trapezoidal membership functions for each input and output value.

\section{Advantages and limitations}

The DSS developed in this study could help road safety decision makers determine the outcome of decisions to be 

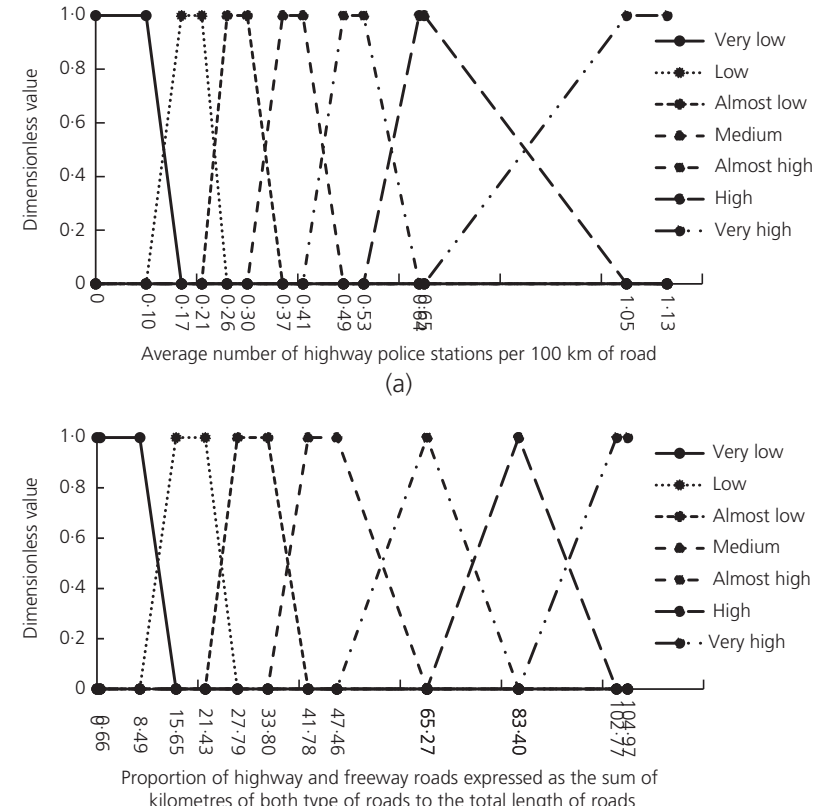

(c)

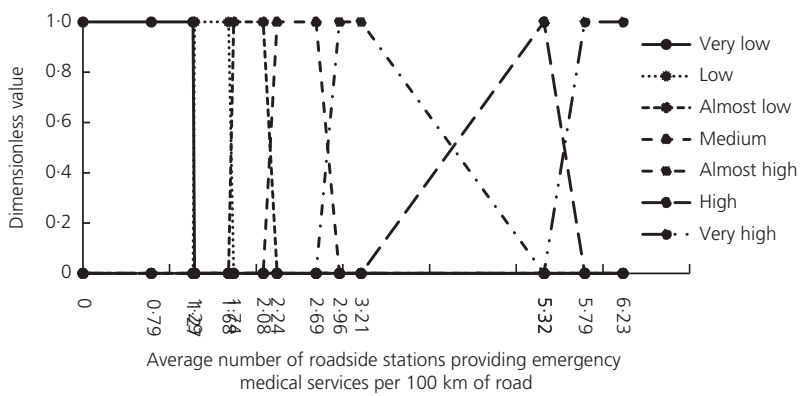

(e)

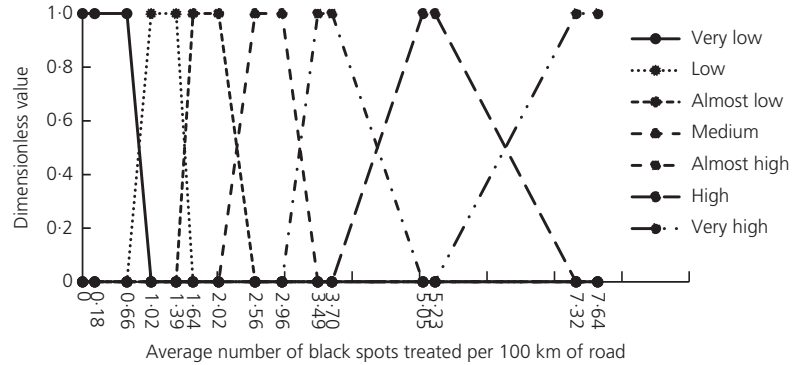

(b)

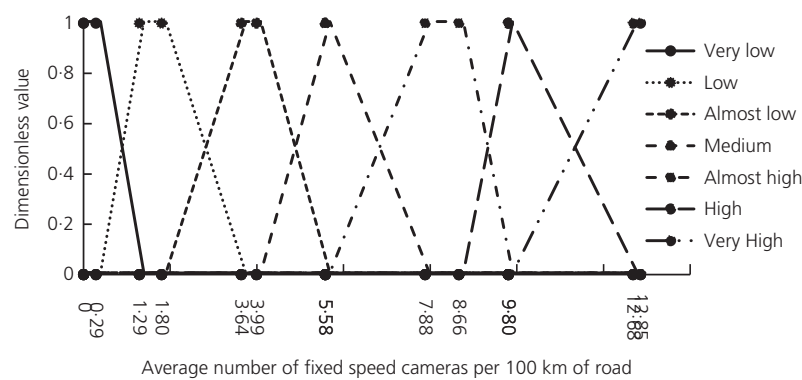

(d)

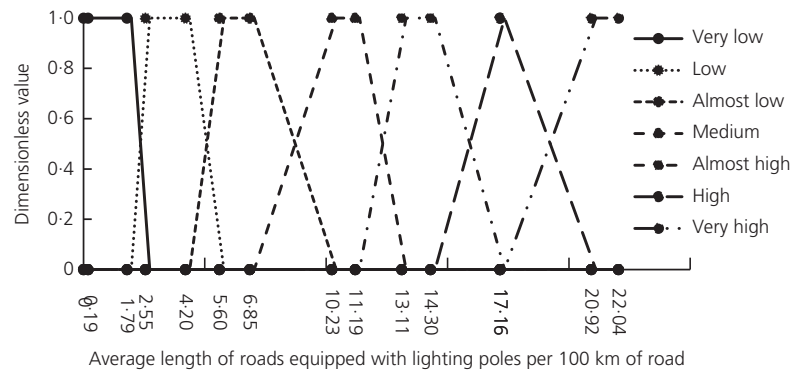

(f)

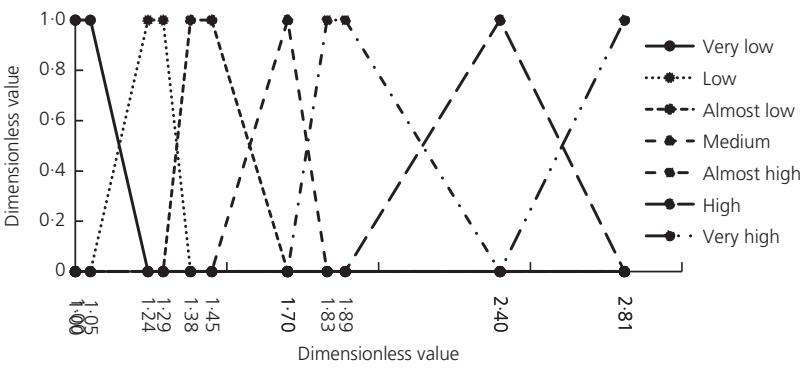

(g)

Figure 2. Membership functions for all input-output indices: (a) index for police patrolling coverage; (b) index for treated black spots; (c) index for freeways and highways; (d) index for speed cameras; (e) index for emergency medical services; (f) index for road lighting projects; (g) index for relative inefficiency

made for alternative road safety measures. The results are stated in term of inefficiency rates with the same essence of DEA inefficiency results, while no repeated DEA needs to be carried out for planning purposes. Moreover, the DSS provides flexibility in selecting strategies that are applicable within limited resources in the sense that an alternative strategy can be quested if the priorities given by the benchmarking process are not applicable in a distinct period. The fuzzy reasoning method allows the creation of models that could not easily be made by conventional statistical models.

The seven-term trapezoidal fuzzy membership function provided in this study resulted in precise responses that correlated well with the main DEA results. To build up a more comprehensive model would require a larger amount of data that best satisfies the rules in the rule block. In doing so, a more reliable 
Table 3. Modified rule block with DoS $\geq 0.001$

\begin{tabular}{|c|c|c|c|c|c|c|c|c|}
\hline Rule & PO term & BS term & H\&F term & SCC term & EMS term & Li term & Ineff term & DoS \\
\hline 1 & VL & VL & $V L$ & VL & VL & $V L$ & VL & 0.032 \\
\hline 2 & VL & VL & $V L$ & VL & VL & VL & $L$ & 0.002 \\
\hline 3 & VL & VL & VL & VL & VL & VL & $\mathrm{AH}$ & 0.001 \\
\hline 4 & VL & $L$ & VL & VL & VL & VL & VL & 0.001 \\
\hline 5 & VL & $L$ & $V L$ & VL & VL & VL & $\mathrm{AH}$ & 0.001 \\
\hline 6 & $\mathrm{~L}$ & VL & $V L$ & VL & VL & VL & $\mathrm{H}$ & 0.001 \\
\hline 7 & L & VL & $\mathrm{VL}$ & VL & VL & VL & $A L$ & 0.001 \\
\hline 8 & L & VL & $\mathrm{VL}$ & VL & VL & VL & $\mathrm{AH}$ & 0.007 \\
\hline $\begin{array}{l}9 \\
\vdots\end{array}$ & $\begin{array}{l}\mathrm{L} \\
\vdots\end{array}$ & $\begin{array}{c}\mathrm{VL} \\
\vdots\end{array}$ & $\begin{array}{l}\mathrm{L} \\
\vdots\end{array}$ & $\begin{array}{c}\text { VL } \\
\vdots\end{array}$ & $\begin{array}{c}\mathrm{VL} \\
\vdots\end{array}$ & $\begin{array}{c}\mathrm{VL} \\
\vdots\end{array}$ & $\begin{array}{c}\mathrm{VL} \\
\vdots\end{array}$ & $\begin{array}{c}0.017 \\
\vdots\end{array}$ \\
\hline 70 & $A L$ & L & $\mathrm{AH}$ & $\mathrm{L}$ & L & $V L$ & $V L$ & 0.001 \\
\hline 71 & $A L$ & L & $\mathrm{AH}$ & $L$ & L & $V L$ & $\mathrm{~L}$ & 0.001 \\
\hline$\vdots$ & $\vdots$ & $\vdots$ & $\vdots$ & $\vdots$ & $\vdots$ & $\vdots$ & $\vdots$ & \\
\hline 277 & VH & $\mathrm{L}$ & $\mathrm{H}$ & $\mathrm{H}$ & $\mathrm{H}$ & $\mathrm{H}$ & VL & 0.001 \\
\hline 278 & VH & $\mathrm{AH}$ & $\mathrm{H}$ & $\mathrm{AH}$ & $\mathrm{VH}$ & VH & $V L$ & 0.011 \\
\hline 279 & VH & $\mathrm{AH}$ & VH & $\mathrm{AH}$ & $\mathrm{VH}$ & VH & $V L$ & 0.004 \\
\hline 280 & VH & $\mathrm{AH}$ & VH & $\mathrm{H}$ & VH & VH & VL & 0.001 \\
\hline 281 & VH & $\mathrm{H}$ & $\mathrm{H}$ & $\mathrm{AH}$ & VH & VH & VL & 0.002 \\
\hline 282 & VH & $\mathrm{H}$ & $\mathrm{H}$ & $\mathrm{H}$ & $\mathrm{VH}$ & $\mathrm{VH}$ & VL & 0.002 \\
\hline 283 & VH & $\mathrm{H}$ & VH & $\mathrm{AH}$ & VH & VH & VL & 0.001 \\
\hline 284 & VH & $\mathrm{H}$ & VH & $\mathrm{H}$ & VH & VH & VL & 0.005 \\
\hline 285 & VH & $\mathrm{H}$ & VH & $\mathrm{VH}$ & $\mathrm{AH}$ & $\mathrm{AH}$ & VL & 0.001 \\
\hline
\end{tabular}

Table 4. Efficiency analysis of different strategies

\begin{tabular}{|c|c|c|c|c|c|c|c|c|c|c|c|c|}
\hline \multirow[b]{2}{*}{ Strategy } & \multicolumn{12}{|c|}{ Target value } \\
\hline & & $\mathrm{PO}$ & & BS & & $\mathrm{H} \& \mathrm{~F}$ & & SCC & & VS & & $\mathrm{Li}$ \\
\hline 0. Do nothing (existing values) & 0.26 & $A L(1)$ & 0.97 & $\begin{array}{r}L(0.85) \\
V L(0.15)\end{array}$ & $68 \cdot 11$ & $\begin{array}{l}\mathrm{AH}(0.84) \\
\mathrm{H}(0.16)\end{array}$ & 1.06 & $\begin{array}{r}L(0.77) \\
V L(0.23)\end{array}$ & $1 \cdot 50$ & $L(1)$ & $1 \cdot 54$ & $\mathrm{VL}(1)$ \\
\hline $\begin{array}{l}\text { 1. More than } 90 \% \text { increase } \\
\text { in lighting facilities }\end{array}$ & 0.26 & $\mathrm{AL}(1)$ & 0.97 & $\begin{array}{r}L(0.85) \\
V L(0.15)\end{array}$ & $68 \cdot 11$ & $\begin{array}{c}\mathrm{AH}(0.84) \\
\mathrm{H}(0.16)\end{array}$ & 1.06 & $\begin{array}{r}L(0.77) \\
V L(0.23)\end{array}$ & $1 \cdot 50$ & $L(1)$ & 2.94 & $L(1)$ \\
\hline $\begin{array}{l}\text { 2. About } 80 \% \text { increase in black } \\
\text { spot treatments and more than } \\
90 \% \text { increase in lighting facilities }\end{array}$ & 0.26 & $\mathrm{AL}(1)$ & $1 \cdot 74$ & $\mathrm{AL}(1)$ & $68 \cdot 11$ & $\begin{array}{l}\mathrm{AH}(0.84) \\
\mathrm{H}(0.16)\end{array}$ & 1.06 & $\begin{array}{r}L(0.77) \\
V L(0.23)\end{array}$ & $1 \cdot 50$ & $L(1)$ & $2 \cdot 94$ & $L(1)$ \\
\hline $\begin{array}{l}\text { 3. Increase in all safety measures } \\
\text { except freeway facilities }\end{array}$ & 0.47 & $\begin{array}{l}\mathrm{AH}(0.75) \\
\mathrm{M}(0.25)\end{array}$ & $2 \cdot 70$ & $M(1)$ & $68 \cdot 11$ & $\begin{array}{c}\mathrm{AH}(0.84) \\
\mathrm{H}(0.16)\end{array}$ & $5 \cdot 55$ & $M(1)$ & 1.93 & $\operatorname{AL}(1)$ & $7 \cdot 63$ & $\begin{array}{r}\mathrm{AL}(0.77) \\
\mathrm{M}(0.23)\end{array}$ \\
\hline
\end{tabular}

Numbers in parentheses show the value of membership functions

Table 5. Typical fuzzy reasoning and defuzzification process for strategy 0 ('do nothing')

\begin{tabular}{|c|c|c|c|c|c|c|c|c|c|c|c|c|c|c|c|c|c|c|}
\hline PO & & BS & & $\mathrm{H} \& \mathrm{~F}$ & & SCC & & EM & & Li & & Min. & Rule no. & Ineff term & DoS & $\mu_{B}(\boldsymbol{\beta})$ & Norm. & Crisp Ineff \\
\hline \multirow[t]{9}{*}{$A L$} & 1 & $V L$ & $0 \cdot 15$ & $\mathrm{AH}$ & 0.84 & VL & 0.23 & L & 1 & VL & 1 & $0 \cdot 15$ & $N A^{a}$ & All terms & 0 & 0 & - & \multirow[t]{9}{*}{$1 \cdot 1455$} \\
\hline & & & & & & L & 0.77 & L & 1 & $V L$ & 1 & 0.15 & NA & All terms & 0 & 0 & - & \\
\hline & & & & $\mathrm{H}$ & $0 \cdot 16$ & $V L$ & 0.23 & $\mathrm{~L}$ & 1 & VL & 1 & 0.15 & NA & All terms & 0 & 0 & - & \\
\hline & & & & & & L & 0.77 & L & 1 & VL & 1 & $0 \cdot 15$ & NA & All terms & 0 & 0 & - & \\
\hline & & L & 0.85 & $\mathrm{AH}$ & 0.84 & $V L$ & 0.23 & L & 1 & $\mathrm{VL}$ & 1 & 0.23 & NA & All terms & 0 & 0 & - & \\
\hline & & & & & & $\mathrm{L}$ & 0.77 & L & 1 & $\mathrm{VL}$ & 1 & 0.77 & 70 & $\mathrm{VL}$ & 0.001 & 0.00077 & 0.50 & \\
\hline & & & & & & & & & & & & & 71 & $\mathrm{~L}$ & 0.001 & 0.00077 & 0.50 & \\
\hline & & & & $\mathrm{H}$ & 0.16 & $V L$ & 0.23 & L & 1 & $V L$ & 1 & $0 \cdot 16$ & NA & All terms & 0 & 0 & - & \\
\hline & & & & & & L & 0.77 & L & 1 & VL & 1 & $0 \cdot 16$ & NA & All terms & 0 & 0 & - & \\
\hline
\end{tabular}

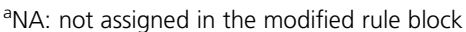

model would be achieved that could predict the outcomes for any given composition of RSPIs. A 2-year database can be used to establish the desired DSS but does not allow the responses for all possible decisions to be found since some may not be supported by the effective rules in the rule block. Furthermore, the approach discussed here can be used for 
Table 6. Comparison of actual and fuzzy predicted inefficiencies

\begin{tabular}{|c|c|c|c|c|c|c|c|c|}
\hline DMU & $\begin{array}{c}\text { Actual } \\
\text { inefficiency }\end{array}$ & $\begin{array}{l}\text { Predicted } \\
\text { inefficiency }\end{array}$ & DMU & $\begin{array}{c}\text { Actual } \\
\text { inefficiency }\end{array}$ & $\begin{array}{l}\text { Predicted } \\
\text { inefficiency }\end{array}$ & DMU & $\begin{array}{c}\text { Actual } \\
\text { inefficiency }\end{array}$ & $\begin{array}{l}\text { Predicted } \\
\text { inefficiency }\end{array}$ \\
\hline 1 & 1.2792 & 1.2645 & 21 & $1 \cdot 1508$ & 1.2645 & 41 & 1.7996 & 1.8615 \\
\hline 2 & 1.9736 & $1 \cdot 8615$ & 22 & 1.0524 & 1.0260 & 42 & 1.0964 & 1.0260 \\
\hline 3 & 1.0000 & 1.0260 & 23 & 1.3746 & 1.4135 & 43 & $1 \cdot 3133$ & 1.2596 \\
\hline 4 & $1 \cdot 1045$ & 1.0260 & 24 & 1.9799 & 1.8615 & 44 & 1.0000 & 1.0260 \\
\hline 5 & 1.0000 & 1.0260 & 25 & 1.7023 & 1.7020 & 45 & 1.8299 & $1 \cdot 3028$ \\
\hline 6 & 1.0000 & 1.0260 & 26 & $1 \cdot 3893$ & 1.4135 & 46 & $1 \cdot 7228$ & $1 \cdot 7818$ \\
\hline 7 & 1.0789 & 1.0260 & 27 & $1 \cdot 1843$ & $1 \cdot 2645$ & 47 & $1 \cdot 1502$ & $1 \cdot 1453$ \\
\hline 8 & $1 \cdot 1307$ & 1.0260 & 28 & $1 \cdot 4452$ & $1 \cdot 1791$ & 48 & 1.0000 & 1.0260 \\
\hline 9 & 1.0876 & 1.0260 & 29 & $2 \cdot 4015$ & $2 \cdot 4020$ & 49 & 1.8136 & 1.8615 \\
\hline 10 & 1.4523 & $1 \cdot 3426$ & 30 & 1.0000 & $1 \cdot 1545$ & 50 & $1 \cdot 2080$ & $1 \cdot 5640$ \\
\hline 11 & $1 \cdot 3412$ & 1.4993 & 31 & $1 \cdot 2844$ & 1.3390 & 51 & $1 \cdot 2362$ & $1 \cdot 2645$ \\
\hline 12 & 1.2357 & 1.2645 & 32 & 1.8778 & $2 \cdot 3353$ & 52 & 1.0000 & 1.0260 \\
\hline 13 & $1 \cdot 3686$ & 1.4135 & 33 & 1.0000 & 1.0260 & 53 & $1 \cdot 2761$ & $1 \cdot 2645$ \\
\hline 14 & 1.0935 & 1.0260 & 34 & 1.0000 & 1.0260 & 54 & 1.8925 & 1.8615 \\
\hline 15 & 1.9330 & 1.5273 & 35 & $1 \cdot 1955$ & 1.2645 & 55 & $1 \cdot 4406$ & 1.4135 \\
\hline 16 & 1.8190 & $1 \cdot 7818$ & 36 & 1.0000 & 1.0260 & 56 & 1.4390 & 1.4135 \\
\hline 17 & $1 \cdot 5899$ & $1 \cdot 7020$ & 37 & 1.0000 & 1.0260 & 57 & $1 \cdot 3801$ & 1.4135 \\
\hline 18 & 1.0042 & 1.0260 & 38 & 1.0000 & 1.0260 & 58 & 1.0000 & 1.0260 \\
\hline 19 & $2 \cdot 8087$ & $2 \cdot 3353$ & 39 & 1.0000 & 1.0260 & 59 & $1 \cdot 7828$ & 1.8615 \\
\hline 20 & 1.2929 & 1.3680 & 40 & 1.4860 & 1.3390 & 60 & 1.0000 & 1.0260 \\
\hline
\end{tabular}

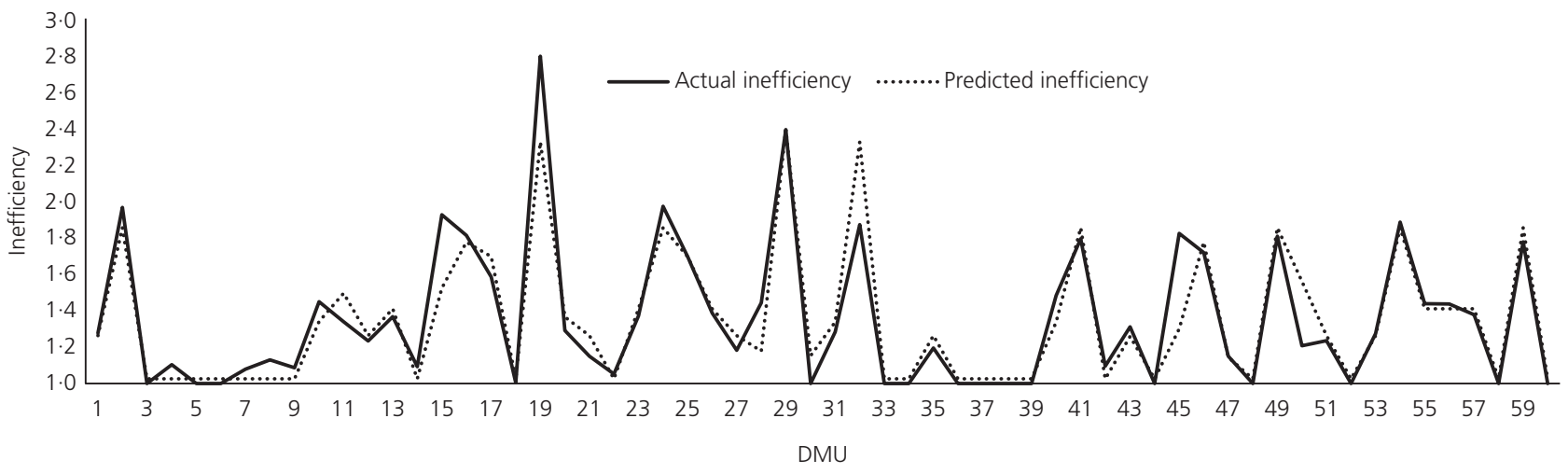

Figure 3. Comparison of actual DEA and fuzzy predicted inefficiencies

short-term decision-making procedures but an extension to the research may allow anticipation of results much further into the future, say 10 years. Such a planning pattern needs an approach powered by hierarchical or stage-based analytical methods such as dynamic programming. Indeed, further research in this area would strongly benefit efficient targetbased planning for road safety improvements.

\section{Conclusions}

This research aimed to create a DSS through which users can monitor previous performance, analyse the existing status and forecast the decisions made to improve system efficiency. The system is designed as a means for planning purposes and for supporting prospective road safety decisions after inefficiency indices have been calculated. Here, the inefficiency index was obtained according to pre-experienced measures implemented throughout the provinces in Iran. The conceptual model contains three major parts: (a) road safety performance evaluation based on DEA, $(b)$ the creation of a fuzzy decision-making system and (c) the formulation of new targets for a region based on its current road safety situation and what-if analyses carried out on the rule-based system.

In this study, 30 different regions in Iran were considered. For each region, 2 years of input and output data were available for a predefined set of road safety indicators. In the first step, a relative inefficiency index was calculated for each province for each year using the DEA method. Each province in each year was defined as a DMU in the DEA. The inefficiency index was defined as the proportion of the weighted sum of outputs (fatality risks) to the weighted sum of inputs (performance indicators). Using the dual model for the road safety DEA model, a target-setting exercise was carried out using the 
extracted dual prices from this model. Having collected the resulting DEA inefficiency values (60 DMUs) and their attributed target values (60 units) in the same knowledge base, a rule base was obtained for the purpose of fuzzy reasoning and decision-making analyses. The combination of all possible fuzzy categories for the seven variables (six antecedents + one consequent) resulted in a rule block of 823543 rules $\left(7^{7}\right)$. For each of these rules in the rule block, the DoS was established based on the data from 30 provinces in two years as well as the optimal targets attributed. The fuzzy reasoning process was then carried out for alternative strategies so that a distinct numerical value of inefficiency could be calculated for each strategy. As the final decision point, the strategy with the lowest inefficiency rate can be selected as the best feasible alternative. In order to verify the accuracy of the results, the estimated results from the fuzzy system were compared with the actual DEA-based inefficiency rates through a correlation analysis. The comparison revealed a correlation factor $\left(R^{2}\right)$ of $94 \%$, which indicates high acceptability of the fuzzy system created by seven qualitative terms in trapezoidal membership functions for each input and output value.

\section{REFERENCES}

Adriaanse A (1993) Environmental Policy Performance Indicators. A Study on the Development of Indicators for Environmental Policy in the Netherlands. Ministry of Housing, Physical Planning and the Environment, Sdu Publishers, The Hague, the Netherlands. Azar A and Faraji H (2008) Fuzzy Management Science, Iran Management and Productivity Studies Center (IMPSC). Mehrban-Nashr Publications, Tehran, Iran.

Bao Q, Ruan D, Shen Y, Hermans E and Janssens D (2012) Improved hierarchical fuzzy Topsis for road safety performance evaluation. Knowledge-Based Systems 32: 84-90.

Cafiso S, Lamm R and La Cava GL (2004) Fuzzy model for safety evaluation process of new and old roads. Transportation Research Record 1881: 54-62.

Cook WD and Seiford LM (2009) Data envelopment analysis (DEA) Thirty years on. European Journal of Operational Research 192(1) $1-17$.

Emrouznejad A, Parker BR and Tavares G (2008) Evaluation of research in efficiency and productivity: a survey and analysis of the first 30 years of scholarly literature in DEA. Socio-Economic Planning Sciences 42(3): 151-157.

ETSC (European Transport Safety Council) (2001) Transport Safety Performance Indicators. ETSC, Brussels, Belgium.

Harris J (2006) Fuzzy Logic Applications in Engineering Science. Springer, Dordrecht, the Netherlands.

Hermans E, Brijs T, Wets G and Vanhoof K (2009) Benchmarking road safety: lessons to learn from a data envelopment analysis. Accident Analysis and Prevention 41(1): 174-182.

Ma Z, Shao C, Wang Y and Ma S (2009) Research on regional road safety evaluation based on fuzzy theory. Proceedings of the 2nd International Conference on Intelligent Computation Technology and Automation, ICICTA '09, Changsha, Hunan, China.

Mehregan M (2006) Quantitative Models in Organizational Performance Evaluation (Data Envelopment Analysis), 2nd edn. Faculty of Management Publications, University of Tehran, Tehran, Iran.

RMTO (Road Maintenance and Transportation Organization) (2010) Highway Transportation Annual Report. Ministry of Road and Transportation, Tehran, Iran
RMTO (2011) Highway Transportation Annual Report. Ministry of Road and Transportation, Tehran, Iran.

Ross TJ (2004) Fuzzy Logic with Engineering Applications. Wiley, Chichester, UK.

RSC (Road Safety Commission) (2010) Highway Transportation Annual Report: Annual Road Fatality Report. Ministry of Road and Transportation, Tehran, Iran.

RSC (2011) Highway Transportation Annual Report: Annual Road Fatality Report. Ministry of Road and Transportation, Tehran, Iran.

RSCI (Road Safety Commission of Iran) (2007) Main performance indicators toward sustainable road safety. In The Act by 31st Meeting of the Road Safety Commission of Iran. Ministry of Road and Transportation, Tehran, Iran.

Shen Y, Li T, Heramns E et al. (2010) A hybrid system of neural networks and rough sets for road safety performance indicators. Soft Computing 14(12): 1255-1263.

Shen Y, Hermans E, Ruan D et al. (2011) A generalized multiple layer data envelopment analysis model for hierarchical structure assessment: a case study in road safety performance evaluation. Expert Systems with Applications 38(12): 15262-15272.

Shen Y, Hermans E, Brijs T, Wets G and Vanhoof K (2012) Road safety risk evaluation and target setting using data envelopment analysis and its extensions. Accident Analysis \& Prevention 48: 430-441.

Shi H (2009) Fuzzy evaluation approach of road traffic safety based on AHP. Proceedings of the International Conference on Future BioMedical Information Engineering (FBIE 2009), Sanya, China.

Wegman $\mathrm{F}$ and Oppe S (2010) Benchmarking road safety performances of countries. Safety Science 48(9): 1203-1211.

\section{How can you contribute?}

To discuss this paper, please email up to 500 words to the editor at journals@ice.org.uk. Your contribution will be forwarded to the author(s) for a reply and, if considered appropriate by the editorial board, it will be published as discussion in a future issue of the journal.

Proceedings journals rely entirely on contributions from the civil engineering profession (and allied disciplines). Information about how to submit your paper online is available at www.icevirtuallibrary.com/page/authors, where you will also find detailed author guidelines. 